\title{
HIGH RISK OF POSTPARTUM HAEMORRHAGE AT BOUAKÉ UNIVERSITY HOSPITAL (NORTH-CENTRAL CÔTE D'IVOIRE)
}

\author{
DOI: http://doi.org/10.26758/11.1.6
}

Zahouo Pascale Ghislaine KOUAMÉ (1), Adou Serge Judicaël ANOUA (1), N’Doumy Noël ABE (1)

(1) Alassane Ouattara University, Côte d'Ivoire

Address correspondence to: Adou Serge Judicaël Anoua, Department of Anthropology \& Sociology, Alassane Ouattara University, BP V18 Bouaké 01, Bouaké, Côte d'Ivoire, Ph. : +225 07070136; Email: anoua_08@yahoo.fr

\begin{abstract}
Objectives. Postpartum haemorrhage is one of several direct causes of maternal death in Côte d'Ivoire. It is recurrent in the department of gynaecology and obstetrics at Bouaké University Hospital (CHU de Bouaké), but little is known to date about the underlying risk factors. The present study aims to describe the levels and trends displayed by the risk factors of postpartum haemorrhage before determining the contributing social factors in the aforesaid department.

Material and methods. This study is retrospective in nature, concerning the period from 2014 to 2016. Data was obtained from delivery records and through individual interviews. The overall approach adopted is an anthropological one.

Results. Postpartum haemorrhage is significant in light of its very high and increasing incidence (22.31\%) among multiparous mothers. Within the latter category, fatal complications are a critical problem, with an annual average estimated at $35.98 \%$ and on the rise. The overall situation is alarming in view of this progressive deterioration. The persistence of the reproductive morbidity is attributable to various economic, social, cultural, and infrastructural factors.

Conclusions. Communicational strategies are proposed as a type of community intervention conducive to social and behavioural change, with multiparous mothers as a priority target group, followed by older mothers in the medium term and by adolescent mothers in the long term. This should raise awareness about high-risk reproductive behaviours and practices as well as the environmental, economic, social, cultural, and infrastructural factors correlated to postpartum haemorrhage, with the ultimate goal of improving the quality and safety of reproductive practices.
\end{abstract}

Keywords: postpartum haemorrhage, reproductive behaviour, high risk, obstetric emergency, maternal morbidity, Côte d'Ivoire.

\section{Introduction}

Postpartum haemorrhage is currently an especially concerning instance of maternal reproductive morbidity. According to $\mathrm{WHO}(2014$, p. 8$)$, it affects about $2 \%$ of parturient women in the world. Its impact on them is enormous. It seems to promote in these women a state of posttraumatic stress such as a feeling of death and loss of control, a bad memory of childbirth, avoidance of elements reminding them of childbirth, sleep disorders (Faure, 2011). In addition, other women suffer from complications of transfusion, resuscitation, and infertility in case of hysterectomy (Deneux-Tharaux, Bonnet, \& Tort, 2014). Sometimes complications such as acute anuric renal failure and inferior vena cava thrombus are highlighted (Deneau, Jean-Michel, Salah, Benyaghla, \& Kalfon, 2017). Furthermore, it is responsible for almost a quarter of all maternal deaths, which makes it the 
leading cause of maternal deaths (WHO, 2014, p. 8). In the majority of low-income countries, its prevalence is especially notable. This is the case of Côte d'Ivoire too, where postpartum haemorrhage is the most frequently observed direct cause of maternal death. Its incidence has been estimated at $42 \%$ of women in the national representative sample in Côte d'Ivoire's National Health Development Plan for 2016-2020 (MSHP, p. 18).

The characteristics of this maternal morbidity are related to several aspects of public and community health. There are in turn conditioned by the financial, geographic, social and material constraints to which mothers are subject (Fenomanana, Riel, Rakotomena, Andrianjatovo, \& Andrianampanalinarivo, 2009). The overlap of these diverse factors adds to the complexity of the issue of maternal morbidity, which the existing literature has approached from multiple perspectives. From a sociodemographic point of view, it has been noted that postpartum haemorrhage correlates with age (Alouini, Randriambololona, \& Randriamboavonjy, 2015) and with multiparity (Mazouz, Sabri, \& Hamadouch, 2018, p. 30), whereas from a medical and healthcare point of view, relevant factors include restricted access to centres for obstetric emergencies and obstetric complications (Mukuna, Okenge, Sepou, \& Modia, 2018). In the latter case, uterine atony and soft tissue tearing or uterine rupture (Diakité, 2015) as well as intervals of oxytocin increase of less than 20 minutes during spontaneous labour (Loscul et al., 2016) have been found to be the most common causes. Sometimes these complications are aggravated by factors such as delays in care. This is often justified by resistance generated by the organization and operation of obstetric emergency services (Faye Dieme et al., 2017).

The health care policy of Côte d'Ivoire aims to reduce postpartum haemorrhage by developing the skills of staff who provide emergency obstetric and neonatal care. The same is true by improving the quality and range of care services in all regions of the country, so that mothers can receive adequate and even optimal treatment. This issue is prominently addressed by the National Health Development Plan for 2016-2020, in its fifth strategic component, pertaining to the health of mothers, new-borns, children, adolescents, and the youth, which sets the objective of improving the health of the aforementioned categories by 2020 and reducing mortality by 50\% (MSHP, 2016, p. $53)$.

However, the implementation of these initiatives and response actions is undeniably limited. In the specific case of the department of gynaecology and obstetrics at Bouaké University Hospital, there are several shortcomings to be pointed out following an exploratory survey of the manager and health workers in the department. These are notably the upsurge of cases of postpartum haemorrhage and delays in providing care in case of an obstetric emergency. The social aspect remains crucial in the search for solutions to these problems. Indeed, there are sociological factors with underlying sociodemographic and epidemiological variables that are of importance for combating the morbidity under discussion. In particular, high-risk reproductive behaviours are a risk factor for postpartum haemorrhage, along with environmental, economic, social and cultural determinants.

It is thus within an anthropological perspective that is formulated the hypothesis that efforts to prevent postpartum haemorrhage must include a dynamic process of long-term health education, aimed at reducing high-risk behaviours and other risk factors. This is considered as a necessity since a mother is the mainstay of the family, by virtue of her role in covering household expenses. Her survival is thus essential because of her productive contributions. The present study aims to describe the levels and trends displayed by the high risk factors for postpartum haemorrhage before determining the social factors that contribute to in the department of gynaecology and obstetrics at Bouaké University Hospital. Thus, for the purpose of the analysis, it appears necessary to situate the incidence and trends of postpartum haemorrhage in adolescent, older, and multiparous mothers, to present the incidence and trends of deaths related to this morbidity in this category of mothers, and finally to expose the social factors associated with its dynamics. Before addressing these matters, a presentation of the methodology is in order. 


\title{
Material and Methods
}

\author{
Scope of the Study
}

The research was carried out in Bouaké University Hospital, in North-Central Côte d'Ivoire. This is the only specialised medical unit for obstetric complications in the region. It is a public, national institution with a threefold vocation - medical care, education, and research in the field of health - and it is equipped with a department for gynaecology and obstetrics according to its 2016 activity report. It is the unit for delivery and obstetric emergencies of this department that was selected as the scope for this study.

\section{Research Type and Population}

The present study has a descriptive and interpretive (Thorne, 2008) approach and a retrospective viewpoint. It was conducted from the perspective of social anthropology, applied to informants from the department of gynaecology and obstetrics. The latter included an obstetriciangynaecologist, a midwife, five women who had been treated for an obstetric emergency, and five relatives of these women. Thus, there was a total of twelve informants in the study, selected for their fluency in French and the experiences with postpartum haemorrhage that they could relate; in other words, they were chosen as a convenience sample. To do this, a basic survey of a list of people present at the time of the survey was used as a sampling technique. They were then interviewed so that the social factors that influence postpartum haemorrhage could be identified. Furthermore, the delivery records for the period 2014-2016 were examined, with a view to determine the levels and trends displayed by postpartum haemorrhage and consequent death in adolescent, older, and multiparous mothers.

\section{Ethics and Data Collection}

For the approval of the research, the scientific board of the Department of Anthropology and Sociology of Alassane Ouattara University in Côte d'Ivoire reviewed and ratified the procedures to be used to get informed verbal consent from the participants of the study. The collected data were subsequently anonymized and could no longer be linked to any individual informant.

The research took place between the $15^{\text {th }}$ of August and the $15^{\text {th }}$ of December of 2016 and consisted of two stages. First, a quantitative analysis of the delivery records made available by the department of gynaecology and obstetrics was carried out. The period under study spanned three years, from 2014 to 2016 and the data was collected following a previously established grid. The numerical data collected represented the variables of age, number of births, maternal death, and postpartum haemorrhage, noted for each mother included in the records. The collection of the data was carried out by three students, each one working on one of the three observation years, in a space allocated to them by the director of the department of gynaecology and obstetrics. This first stage was followed by a qualitative investigation performed with the aid of an interview guide focused on the social factors relevant to haemorrhage in parturients, during or following childbirth. The interviews were conducted individually with the aforementioned twelve informers, namely the obstetriciangynaecologist, the midwife, the five women who had experienced postpartum haemorrhage, and five friends and relatives thereof, and were organised according to the availability of the respondents. 


\section{Data Management and Analysis}

The data drawn from the delivery records were digitally analysed with the use of the program Epi Info 5.3. The grids were validated once the delivery records had been surveyed and the data representing the variables of age, number of births, maternal death, and postpartum haemorrhage were coded before being entered into the chosen software on a computer. The statistical analysis that was then conducted served to identify the levels and trends of postpartum haemorrhage in adolescent, older, and multiparous mothers, as well as the mortality rate associated with this morbidity in these three categories of mothers. The relevance of the analysis methods rests upon the theory of reproductive transition, which is a reduced model of demographic dividend, at the scale of a healthcare network (Abé, 2013). This theory led to the establishment of a priority ranking of the response actions proposed, reflecting the respective risk levels of the categories of mothers.

As for the data obtained by means of the interview guide, they were tallied manually and subjected to a thematic content analysis (Paille \& Mucchielli, 2012). Within the information gleaned in this way, the main properties and trends of the social factors contributing to postpartum haemorrhage were pinpointed. These were then further analysed so that their significance could be elucidated. To this end, the theory of personal constructs set forth by Carré and Fenouillet (2019) was relied upon, for a more insightful interpretation of the personal and subjective experiences of postpartum haemorrhage that were recorded. In the following, there will be presented the results of the study and what they have revealed about the department of gynaecology and obstetrics at Boauké University Hospital.

\section{Results}

The results can be broken down into three sets: 1) incidence and trends of postpartum haemorrhage per category of mothers in the period 2014-2016;2) incidence and trends of maternal mortality due to postpartum haemorrhage per category of mothers in the period 2014-2016; and 3) the social factors correlated to postpartum haemorrhage.

\section{Postpartum Haemorrhage per Category of Mothers}

\section{Table 1}

Incidence and trends of postpartum haemorrhage in mothers from 2014 to 2016

\begin{tabular}{|c|c|c|c|c|c|c|c|c|c|}
\hline \multicolumn{10}{|c|}{ Postpartum haemorrhage in adolescent, older, and multiparous mothers } \\
\hline Bouaké & \multicolumn{2}{|c|}{$\begin{array}{l}\text { PPH in } \\
\text { mothers }\end{array}$} & \multicolumn{2}{|c|}{$\begin{array}{l}\text { In } \\
\text { adolescent } \\
\text { mothers } \\
(<19 \text { yo })\end{array}$} & \multicolumn{2}{|c|}{$\begin{array}{l}\text { In older } \\
\text { mothers } \\
(>35 \text { yo) }\end{array}$} & \multicolumn{2}{|c|}{$\begin{array}{l}\text { In } \\
\text { multiparous } \\
\text { mothers } \\
\text { (> } 4 \text { births) }\end{array}$} & \multirow[t]{2}{*}{$\begin{array}{l}\text { Dominant } \\
\text { risk factor }\end{array}$} \\
\hline Year & $n$ & $\%$ & $n$ & $\%$ & $n$ & $\%$ & $n$ & $\%$ & \\
\hline 2014 & 105 & 13.20 & 09 & 8.57 & 17 & 16.19 & 23 & 21.90 & \\
\hline 2015 & 101 & 12.47 & 07 & 6.93 & 21 & 20.79 & 20 & 19.80 & \\
\hline 2016 & 107 & 9.69 & 11 & 10.20 & 25 & 23.36 & 27 & 25.23 & \\
\hline $\begin{array}{l}\text { Yearly } \\
\text { average }\end{array}$ & \multicolumn{2}{|c|}{11.78} & \multicolumn{2}{|c|}{8.59} & \multicolumn{2}{|c|}{20.11} & \multicolumn{2}{|c|}{22.31} & Multiparity \\
\hline $\begin{array}{l}\text { Trend } \\
\text { Status }\end{array}$ & \multicolumn{2}{|c|}{ Decreasing } & \multicolumn{2}{|c|}{ Increasing } & \multicolumn{2}{|c|}{$\begin{array}{l}\text { Increasing } \\
\text { Alarming }\end{array}$} & \multicolumn{2}{|c|}{ Increasing } & \\
\hline
\end{tabular}


In the department of gynaecology and obstetrics at Bouake University Hospital, postpartum haemorrhage displayed a high average incidence of $11.78 \%$ per year, albeit with an apparent decrease between successive years.

Although it appeared to be relatively lower for adolescent mothers $8.59 \%$ and older mothers $20.11 \%$, it exhibited to be more significant for its high $22.31 \%$ for multiparous mothers.

On the whole, postpartum haemorrhage predominantly affected multiparous mothers. However, the overall state of affairs and its trends with a gradual rise over time observation period 2014-2016 are deplorable in the case of adolescent, older, and multiparous mothers alike.

In the following subsection, there will be presented the patterns of maternal mortality due to postpartum haemorrhage in each category of mothers.

Maternal Mortality Due to Postpartum Haemorrhage per Category of Mothers

Table 2

Incidence and trends of maternal mortality due to postpartum haemorrhage in from 2014 to 2016

Mortality due to postpartum haemorrhage in adolescent, older, and multiparous mothers

\begin{tabular}{|c|c|c|c|c|c|c|c|c|c|}
\hline \multirow{2}{*}{$\begin{array}{l}\text { Bouaké } \\
\text { Year }\end{array}$} & \multicolumn{2}{|c|}{$\begin{array}{l}\text { Maternal } \\
\text { deaths due to } \\
\text { PPH }\end{array}$} & \multicolumn{2}{|c|}{$\begin{array}{l}\text { In adolescent } \\
\text { mothers } \\
(<19 \text { yo })\end{array}$} & \multicolumn{2}{|c|}{$\begin{array}{l}\text { In older } \\
\text { mothers } \\
(>35 \text { yo })\end{array}$} & \multicolumn{2}{|c|}{$\begin{array}{l}\text { In multiparous } \\
\text { mothers } \\
\text { (> } 4 \text { births })\end{array}$} & \multirow[t]{2}{*}{$\begin{array}{l}\text { Dominant } \\
\text { risk factor }\end{array}$} \\
\hline & $n$ & $\%$ & $n$ & $\%$ & $n$ & $\%$ & $n$ & $\%$ & \\
\hline 2014 & 10 & 27.78 & 0 & 0.00 & 3 & 30.00 & 4 & 40.00 & \\
\hline 2015 & 15 & 36.58 & 1 & 6.67 & 5 & 33.33 & 5 & 33.33 & \\
\hline 2016 & 24 & 39.34 & 2 & 7.69 & 9 & 34.61 & 9 & 34.61 & Mul \\
\hline $\begin{array}{l}\text { Yearly } \\
\text { average }\end{array}$ & \multicolumn{2}{|c|}{31.57} & \multicolumn{2}{|c|}{4.79} & \multicolumn{2}{|c|}{32.65} & \multicolumn{2}{|r|}{35.98} & iny \\
\hline $\begin{array}{l}\text { Trend } \\
\text { Status }\end{array}$ & \multicolumn{2}{|c|}{ Increasing } & \multicolumn{2}{|c|}{ Increasing } & \multicolumn{2}{|c|}{$\begin{array}{r}\text { Increasing } \\
\text { Alarming }\end{array}$} & \multicolumn{2}{|c|}{ Increasing } & \\
\hline
\end{tabular}

There was a high risk of maternal deaths due to postpartum haemorrhage, with an average yearly incidence of $31.57 \%$ and an increase over the three observation years in the department of gynaecology and obstetrics at Bouaké University Hospital.

Adolescent mothers displayed per year a relatively low average rate of $4.79 \%$, and older mothers a high average frequency of $32.65 \%$. The highest average yearly incidence of deaths due to postpartum haemorrhage, $35.98 \%$, was recorded in the case of multiparous mothers.

Thus, maternal mortality due to postpartum haemorrhage was especially significant in the case of multiparous mothers, with the overall situation being alarming for all three categories of mothers under consideration.

In the following subsection, there will be turned to the social factors that contribute to postpartum haemorrhage.

\section{Social factors that contribute to postpartum haemorrhage}

The analysis of the data has shown that a parturient's decision whether or not to seek obstetric care could depend on her willingness to receive emergency care, since a parturient or her family might not have the necessary financial resources to pay for the healthcare provided in case of an emergency. This was evident in the dissatisfaction with the cost of transport by ambulance voiced 
by several women referred to the centre for obstetric emergencies because of postpartum haemorrhage. This is one of the reasons that the women refrained from requesting obstetric services or deferred their decision to do so. One of them lamented the high expenses as follows:

When my giving birth started to wear out the midwife, she asked for me be to driven to the ER in an ambulance, but my husband didn't know where to get the 20,000 francs [XOF] that they wanted to charge me for the trip in the ambulance. With the help of relatives, we mustered the money, but once I got to the ER, there was expensive medication to pay for. So it's because of all of that that some women would die when they lost a lot of blood because of a complication of childbirth (Interview with a woman referred to the centre for obstetric emergencies in Bouaké).

Such issues also led women to postpone their decision to visit a health centre, which in turn aggravates the risk of maternal death, as the obstetrician-gynaecologist from the department of gynaecology and obstetrics at the Bouaké University Hospital who was interviewed explained in the following words:

Putting off visits to the unit for obstetric emergencies was one of the principal reasons for death due to blood loss in parturients. Their reluctance was due to their insufficient financial means or their preference for a home birth, among other factors (Interview with an obstetriciangynaecologist in Bouaké).

Dismissing the warning signs of postpartum haemorrhage must also be recognised as a risk factor for the women that were sent to the centre for obstetric emergencies. Indeed, some of the pregnant women had experienced haemorrhage prior to delivery, which could be a sign of a problem with the placenta which poses a risk of later postpartum haemorrhage. This could kill the mother or the fetus, but the women who had been sent to the emergency centre did not perceive their symptoms in this way. In their view, bleeding during or after childbirth was a consequence of the diet of the parturient during her pregnancy, as one of the respondents affirmed:

If a woman bleeds after giving birth, it's because she's been eating food which custom forbids. That's what she must have been doing. So if she gets pregnant again, she should stop eating everything that's forbidden for a pregnant woman, otherwise she'll bleed again (Interview with a woman referred to the centre for obstetric emergencies in Bouaké).

Such lack of awareness is thus also a risk factor, considering that it had delayed the expectant mothers' decision to seek obstetric care and thus increased the chances of subsequent postpartum haemorrhage.

Independently of such delays in seeking emergency care, the very access to such care could be impeded by a lack of means of transport at the parturient's disposition. Indeed, some parturients might arrive in time at the maternity hospital closest to their place of residence, only to find that that there was no ambulance available to drive them to the centre for obstetric emergencies. This would aggravate the risk of obstetric complications such as postpartum haemorrhage. A relative of a woman referred to the centre for obstetric emergencies recounted this kind of experience:

My niece was referred to the ER but she died as a result of profuse bleeding after giving birth. First, when we got to the village hospital, she gave birth normally, but then they said that she was bleeding and that she would have to be taken to the ER. There was no ambulance and we had trouble finding a car quickly. The road was also in poor condition, so by the time we got to the ER, she was already dead (Interview with the relative of a woman referred to the centre for obstetric emergencies in Bouaké). 
This example proves that access to emergency obstetric care may be belated. Inadequate organisation and management also stand out as a factor conducive to delays in providing medical care to parturients. In particular, the dysfunctionality of the referral system exacerbates the risk of postpartum haemorrhage by occasioning such delays. Furthermore, the healthcare staff declared that their equipment and supplies and the range of services they could provide were often meagre. The midwife interviewed illustrated this deficiency as follows:

In the pharmacy, the lack of essential medication like magnesium sulphate, the scarcity of fresh frozen plasma, and the untimely shortage of blood were greatly to be deplored (Interview with a midwife at the centre for obstetric emergencies in Bouaké).

It is thus apparent that among the factors which discourage seeking obstetric care, limited access and supplies are notable obstacles.

\section{Discussions}

Two main facts merit a detailed examination, namely the high risk of postpartum haemorrhage at the department of gynaecology and obstetrics at Bouaké University Hospital and the social factors that contribute to this reproductive morbidity.

The risk of postpartum haemorrhage is the most severe in case of multiparity, since this morbidity was especially prevalent in mothers who had given birth to more than four children. In Faure's study (2011) of postpartum haemorrhage in France, it is mentioned that anomalies in uterine contractility caused by multiparity occur in $59 \%$ of cases of postpartum haemorrhage (p. 13). Additionally, in Diallo's study (2012) of postpartum haemorrhage in Mali, it is noted that grand multiparity heightens the risk of improper uterine contraction and retraction, which can then give rise to postpartum haemorrhage (p. 30). Taking these data into account, one sees why multiparity was an important determinant of postpartum haemorrhage as a reproductive morbidity in the department of gynaecology and obstetrics at Bouaké University Hospital.

In this medical unit, postpartum haemorrhage exhibited the highest rate $(22.31 \%)$ in multiparous mothers, with a tendency to increase over time, observed in the period 2014-2016. The incidence and trends of this reproductive morbidity in multiparous mothers were thus quite catastrophic. Similar observations have been made by Randriambelomanana et al. (2011), in a study of 26 women having undergone an obstetric hysterectomy, in which grand multiparas were most at risk of needing this procedure, which followed postpartum bleeding in $19 \%$ of the total cases. Belaidi, Benchachou, and Bennabi (2015), in turn, report a rate of postpartum haemorrhage of $56.71 \%$ in multiparous mothers in their study of the frequency of the risk factors for this complication in Algeria (p. 55). On the other hand, Descargues, Pitette, Gravier, Roman, and Lemoine (2001) indicate that primiparity is also a factor that significantly increases the risk of postpartum haemorrhage. Similarly, Nikiema (2011) notes in his study that $36 \%$ of postpartum haemorrhage cases were primiparas, more numerous than the multipara making up $6.8 \%$ (p. 80).

It is thus apparent that this reproductive morbidity affects all mothers regardless of their parity. However, considering that all pregnancies entail a risk of death, repeated procreation increases this risk. That is why multiparous mothers have stood out as a risk category, including through their mortality rate in case of postpartum haemorrhage in the department of gynaecology and obstetrics at Boauké University Hospital, especially since the incidence of mortality due to postpartum haemorrhage among multiparous mothers was found to be clearly increasing in the observation period 2014-2016, with a high annual average of 35.98\%. Consequently, the situation was particularly alarming. Multiparous mothers were most at risk of death due to postpartum haemorrhage.

Multiparity as a risk factor of maternal death is reported by Mahbouli et al. (2003), with $40 \%$ of the cases being attributable to immediate or delayed postpartum haemorrhage. Similarly, for 
Roman et al. (2004), grand multiparity was an obstetric and neonatal excess risk, presumably in part because it increased the likelihood of maternal death due to postpartum haemorrhage, and Fenomanana et al. (2009) claim in a study aimed at the identification of risk factors for maternal death that multiparity significantly correlated with the reproductive morbidity under discussion. Finally, Mbeva, Karemere, Prudence, Nyavanda, and Mundama (2018), in their study aimed at determining the causes and circumstances of maternal deaths in hospital conditions, find that bleeding was the leading cause of death, accounting for $63.4 \%$ of cases, out which $40 \%$ fell in the category of multiparous mothers.

Though it has been recognised that multiparity is a significant risk factor for the occurrence of postpartum haemorrhage and consequent death, the fact remains that multiple social factors contribute to this reproductive morbidity. The relevant social factors can be categorised as three types of delays: a delay in deciding to seek obstetric care, a delay in transport to the emergency department, and a delay in the provision of care to parturients.

As far as the delay in deciding to seek obstetric care is concerned, it is first of all due to the difficulty of covering the expenses associated with the transfer to the emergency department, as reported by the women interviewed who had been admitted to the department of gynaecology and obstetrics at Bouaké University Hospital. In particular, patients need to pay the cost of the fuel for the trip and of the services provided by the driver of the ambulance, if one is at all available. In default of an ambulance, they would be compelled to engage the services of a private driver, often beyond their means. Concrete figures are provided by Thiam (2014), who reveals that the cost of the transfer to an obstetric department due to bleeding ranges between 25,000 and 30,000 XOF for patients driven directly from a rural health post, reaching up to 50,000 for those using public transport. He explains that these prices prevent low-income patients from Senegal from accessing emergency obstetric care. The situation is similar in Mali: Cissé (2014) reports that referrals to the department of gynaecology and obstetrics of the health centre in Markala due to bleeding in the third trimester involved direct transport of the parturients at a high cost, more than some of the families could afford; hence, the eventual admission to the emergency department of many parturients would be delayed for hours (pp. 78).

Besides the difficulty of covering the expenses associated with a transfer to an obstetric department, ignorance of the warning signs of postpartum haemorrhage also contributes to the delay in a parturient's decision to seek emergency obstetric care. Furthermore, the interviews conducted for the present study clarified that the persistence of traditional social attitudes discourages recourse to such care. Such unfavourable social circumstances have been pinpointed as a risk factor for postpartum haemorrhage by Subtil, Sommé, Ardiet, and Depret-Mosser (2004). The period of pregnancy itself is often a target of prejudice and other cultural constraints which hinder access to emergency obstetric care (Sepou et al., 2011, p. 7). In the context of the department of gynaecology and obstetrics at Bouaké University Hospital too, insufficient financial means compounded by unawareness of the warning signs of postpartum haemorrhage contribute to delaying the decision to seek obstetric care which might result in a referral due to postpartum haemorrhage.

As for the delay in reaching the emergency department, the respondents interviewed at the department of gynaecology and obstetrics at Bouaké University Hospital agreed that accessing emergency care was indeed difficult. They cited the lack of means of transport as the main problem. In this regard, Sepou et al. (2011) have underscored that even when there are ambulances available in certain medical units in the Central African Republic, they often fail to provide transport to the referred patients, because the attending expenses need to be covered by the relatives of the latter, who are essentially destitute (p. 7). In his thesis regarding Mali, Cissé (2014) additionally points out the scarcity of modern means of transport for patients referred due to an obstetric emergency, as well as the defectiveness of the vehicles used and the poor condition of the roads between the community health centres and the maternity hospitals, both of which impede the transport of patients which present bleeding in the third trimester (p. 7). Moreover, Fofana (2018) notes that the numerous 
patients transported by taxi, mostly due to immediate postpartum haemorrhage, without an accompanying medical professional, arrived from medical units which do not have ambulances at their disposition (p. 75). In light of these facts, it is indisputable that in case of postpartum haemorrhage, the precarious transport conditions are a factor that prolongs the delay in reaching the emergency centre of the department of gynaecology and obstetrics at Bouaké University Hospital too.

Lastly, as regards the delay in the provision of care to parturients, the participants interviewed at the department of gynaecology and obstetrics at Bouaké University Hospital attributed it to inadequate management, as well as insufficient equipment and medications in the emergency centre. Kéïta (2008) also points out insufficient supplies in the department of gynaecology and obstetrics of the referral health centre of Commune V of the District of Bamako: a shortage of emergency products and blood which is a serious obstacle to the efficient treatment of patients which present bleeding in the third trimester of their pregnancy (p. 50). Similarly, Adjoby et al. (2014) identify belated blood transfusion as a factor contributing to mortality in patients admitted for an obstetric emergency. Morau, Ducloy, Le Roux, and Weber (2018), in turn, draws attention to organisational faults in the treatment of postpartum haemorrhage in France. The suboptimal aspects of the emergency obstetric care that he identifies include delays in making a diagnosis, treating internal bleeding, and starting resuscitation procedures, as well as insufficient prenatal orientation of the patients towards appropriate medical centres and improper coordination among the medical staff. Based on the same French data, Tessier, Leroux, and Guseva-Canu (2017) indicate that the provision of emergency obstetric care is more dysfunctional in the case of patients in a state of socioeconomic precarity, which increases the risk of maternal death due to morbidities such as postpartum haemorrhage. All these studies present situations analogous to the correlation between inadequate management and the delay in the provision of care to patients experiencing postpartum haemorrhage at the department of gynaecology and obstetrics at Bouaké University Hospital.

\section{Conclusions}

Postpartum haemorrhage is a morbidity that predominantly affects multiparas rather than older or adolescent mothers. In the triennium studied at Bouaké University Hospital, the yearly average of postpartum haemorrhage was $22.31 \%$, with a rise between successive years, while the average yearly rate of consequent maternal deaths was $35.98 \%$, with the same tendency to increase. In this case study, the trend of this morbidity and of the associated mortality was alarming especially among multiparous mothers, because of the clearly growing rates. These bleak figures at the department of gynaecology and obstetrics at Bouaké University Hospital are partly due to social factors such as insufficient financial resources, ignorance of the warning signs of postpartum haemorrhage, precarious transport conditions, and inadequate management. The enumerated factors contribute to delays in the decision to seek out obstetric care, in transport to the centre for obstetric emergencies, and in the provision of care at the aforementioned department to parturients presenting postpartum haemorrhage, which in turn exacerbate this reproductive morbidity. These results raise the question of what measures can be taken and how they could be implemented in order to accelerate the reduction of the incidence of postpartum haemorrhage and the mitigation of its high risk factors? A concrete solution to the problem could be the planning of communicational strategies that could induce social and behavioural change, as a form of community intervention. The response action must furthermore respect an order of priority. The category of mothers to be targeted as a first priority would be multiparas, due to the especially high incidence of postpartum haemorrhage and consequent death that they exhibit. The second category would be older mothers, to be targeted in the medium term, as they also present a high rate of postpartum haemorrhage and consequent death. Finally, the third category of mothers, to be targeted in the long term, are adolescent mothers, in view of their intermediate rate of postpartum haemorrhage and consequent death. The population in question needs 
to be led to intelligently re-examine their high-risk reproductive behaviours and practices, as well as the environmental, economic, social, and cultural factors that contribute to postpartum haemorrhage. It is only in light of real, identified problems that appropriate action can be envisaged and carried through with the ultimate goal of increasing the quality and safety of reproductive practices. Furthermore, it would be interesting to carry out a survey on the sociological logics underlying the differences in morbidity in these different social categories. It would make it possible to highlight the explanatory model of postpartum haemorrhage in adolescent, older, and multiparous mothers, and their incidence of understanding of this morbidity. However, it should be noted at the outset that an interpretative approach may be used in this study. In this case, this orientation presents itself as an opportunity to shed relevant light on the risk factors for the occurrence of postpartum haemorrhage outside of the demographic, economic and logistical deficit variables. This perspective is defined as an openness to conflicts of representation or targeted contradictions between lived cultural practices and public health norms in relation to the postpartum haemorrhage. This approach would make it possible to act on these points of impact in order to achieve the desired change to reduce the risk factors for this morbidity.

\section{Acknowledgements}

Authors wish to express their gratitude to the women referred to the centre for obstetric emergencies due to postpartum haemorrhage as well as their relatives for their participation in the present study and the many hours they set aside to this end. They would also like to thank the director of the department of gynaecology and obstetrics at Bouaké University Hospital as well as the obstetrician-gynaecologist and the midwife who were interviewed, for their availability and their cooperation during the period of data collection.

\section{Conflicts of Interest}

The authors have no conflict of interest to declare.

\section{References}

1. Abe, N. N. (2013). La théorie de la transition génésique. Un outil de l'observatoire de la santé maternelle et infantile en Afrique. [The theory of reproductive transition. A tool of the observatory of maternal and child health in Africa]. Abidjan: les Éditions Balafons. Retrieved $\begin{array}{llll}\text { September } & 22, & 2020 & \text { from }\end{array}$ https://books.google.ci/books/about/La_th\%C3\%A9orie_de_la_transition_g\%C3\%A9n\%C3 $\%$ A9sique.html?id=A0fDoAEACAAJ\&redir_esc=y

2. Adjoby, R., Konan, J., Alla, C., Nguessan, Y. F., Loue, V., Ahounkeng, N. P., Kouame, A., Andriamandimbison, Z. N., Effoh, D., \& Kouakou, F. (2014). Urgences transfusionnelles et décès maternels en Afrique noire: à propos de 16 cas au CHU de Cocody (Abidjan). [Emergencies blood transfusion and maternal death in black Africa: about 16 cases at the university teaching hospital of Cocody (Abidjan)]. Revue Africaine d'Anesthésiologie et de Médecine d'Urgence, Tome 19 n¹-2014, 82-87. Retrieved September 22, 2020 from https://web-saraf.net/IMG/pdf/corps_journal_definitif_tome_19_n_1.pdf\#page=82

3. Alouini, S., Randriambololona, D., \& Randriamboavonjy, R. (2015). Facteurs de risques de la grossesse, de l'accouchement et du post-partum des adolescentes dans le département du Loiret. [Risk factors of teenage pregnancies, deliveries and post-partum in the department of Loiret]. Journal de Gynécologie Obstétrique et Biologie de la Reproduction, 44(5), 443-450. https://doi.org/10.1016/j.jgyn.2014.07.004. 
4. Belaidi, M. A., Benchachou, R., \& Bennabi, W. (2015). L'hémorragie de la délivrance. [Postpartum haemorrhage]. Doctoral dissertation. Université Abou Bekr Belkaîd, République Algérienne Démocratique et Populaire. Retrieved September 21, 2020 from http://dspace.univ-tlemcen.dz/handle/112/8485

5. Carré, P., \& Fenouillet, F. (2019). Traité de psychologie de la motivation: Théories et pratiques. [Motivational Psychology Treaty: Theories and Practices]. Malakoff, France: Dunod. Retrieved September 22, 2020 from https://www.dunod.com/sciences-humaines-etsociales/traite-psychologie-motivation-theories-et-pratiques-0

6. Cissé, B. (2014). Evaluation du système de référence/évacuation des urgences obstétricales au CSRéf de Markala. [Evaluation of the reference/evacuation system for obstetric emergencies at the CSRéf in Markala]. Thèse de Médecine, Université des sciences, des techniques et des technologies de Bamako, Mali. Retrieved September 22, 2020 from https://www.bibliosante.ml/handle/123456789/604

7. Deneau, P., Jean-Michel, V., Salah, A. B., Benyaghla, S. A., \& Kalfon, P. (2017). Nécrose corticale rénale bilatérale et thrombose de la veine cave inférieure compliquant une hémorragie de la délivrance chez une primipare âgée de 16 ans. [Bilateral renal cortical necrosis and inferior vena cava thrombosis in post-partum haemorrhage in a 16-year-old first pregnancy woman]. Anesthésie \& Réanimation, 3(1), 92-94. https://doi.org/10.1016/j.anrea.2016.10.008.

8. Deneux-Tharaux, C., Bonnet, M. P., \& Tort, J. (2014). Épidémiologie de l'hémorragie du post-partum. [Epidemiology of post-partum haemorrhage]. Journal de Gynécologie Obstétrique et Biologie de la Reproduction, 43(10), 936-950. https://doi.org/10.1016/j.jgyn.2014.09.023.

9. Descargues, G., Pitette, P., Gravier, A., Roman, H., \& Lemoine, J. P. (2001). Les hémorragies non-diagnostiquées du post-partum. [Missed diagnosis of haemorrhage in the postpartum period]. Journal de Gynécologie Obstétrique et Biologie de la Reproduction, 30(6), 590-600. Retrieved September 21, 2020 from https://www.em-consulte.com/article/114227/article/leshemorragies-non-diagnostiquees-du-post-partum

10. Diakité, A. (2015). Décès maternels par hémorragie du post-partum immédiat au CSREF CV de 2009 à 2013. [Maternal deaths by immediate postpartum haemorrhage at CSREF CV from 2009 to 2013]. Thèse de Médecine. Université des Sciences Techniques et Technologies de Bamako, Mali. Retrieved November 10, 2020 from https://www.bibliosante.ml/handle/123456789/772

11. Diallo, T. D. B. (2012). Prise en charge des hémorragies du post-partum immédiat dans le service de gynécologie obstétrique du centre de santé de référence de la commune $\mathrm{V}$ du District de Bamako. 2010-2011. [Management of immediate postpartum haemorrhages in the obstetric gynecology service of the reference health center of commune V of the District of Bamako. 2010-2011]. Thèse de Médecine. Université de Bamako, Mali. Retrieved September 21, 2020 from https://www.bibliosante.ml/handle/123456789/1445

12. Faure, G. (2011). Vécu d'une hémorragie grave de la délivrance: impact sur le désir ultérieur de grossesse. [Experienced with severe postpartum haemorrhage: impact on the subsequent desire for pregnancy]. Gynécologie et obstétrique. Mémoire de Diplôme d'État de SageFemme. Université Paris Descartes. Retrieved September 21, 2020 from https://dumas.ccsd.cnrs.fr/dumas-00620100

13. Faye Dieme, M. E., Gassama O., Diouf, A. A., Thiam Coulibaly, M., Tine M. N., Ndiaye, A., Mall, I., Moreira, P. M., Diouf, A., \& Moreau, J. C. (2017). Prise en charge et pronostic des 
hémorragies du post-partum immédiat dans un Centre de Santé de Niveau II de Dakar (Sénégal). [Management and prognosis of immediate postpartum haemorrhage at a level II Health Center in Dakar (Senegal)]. Journal de la SAGO, 18(2), 27-34. Retrieved November 10, 2020 from http://jsago.org/index.php/jsago/article/view/14/15

14. Fenomanana, M. S., Riel, A. M., Rakotomena, S. D., Andrianjatovo, J. J., \& Andrianampanalinarivo, H. R. (2009). Les facteurs de risque de mortalité par hémorragies du post-partum à la Maternité de Befelatanana-CHU Antananarivo-Madagascar. [The risk's factors of mortality by post-partum haemorrhage at the Maternity of Befelatanana - University Hospital of Antananarivo Madagascar]. Revue d'anesthésie-réanimation et de médecine d'urgence, 1(3), 4-7. Retrieved September 21, 2020 from http://www.rarmu.org/articles/HPP.pdf

15. Fofana, N. G. (2018). Evaluation du système de référence/évacuation des urgences obstétricales au CS réf CIV du district de Bamako. [Evaluation of the reference/evacuation system for obstetrical emergencies at the CS ref CIV in the Bamako district]. Thèse de Médecine, Université des sciences, des techniques et des technologies de Bamako, Mali. Retrieved September 22, 2020 from https://www.bibliosante.ml/handle/123456789/1953

16. Keïta, M. I. (2008). Hémorragies du 3ème trimestre de la grossesse dans le service de gynécologie-obstétrique du Centre de Santé de Référence de la Commune V du District de Bamako. [Haemorrhages in the 3rd trimester of pregnancy in the gynecology-obstetrics service of the Reference Health Center of the Commune V of the District of Bamako]. Thèse de médecine, Université Bamako. Retrieved September 22, 2020 from http://citeseerx.ist.psu.edu/viewdoc/download?doi=10.1.1.459.1341\&rep=rep1\&type=pdf

17. Loscul, C., Chantry, A. A., Caubit, L., Deneux-Tharaux, C., Goffinet, F., \& Le Ray, C. (2016). Association entre les intervalles d'augmentation de l'oxytocine pendant le travail et le risque d'hémorragie du post-partum. [Association between oxytocin augmentation intervals and the risk of postpartum haemorrhage]. La Revue Sage-Femme, 15(5), 238-245. https://doi.org/10.1016/j.sagf.2016.09.004.

18. Mahbouli, S., Basli, M., Messaoudi, F., Messaoudi, I., Chibani, M., \& Rachdi, R. (2003). La mortalité maternelle: épidémiologie, facteurs de risque et évitabilité. À propos de dix cas. [Maternal mortality: epidemiology, risk factors and evitability. About ten cases]. Gynécologie obstétrique \& fertilité, 31(12), 1018-1023. https://doi.org/10.1016/j.gyobfe.2003.08.018.

19. Mazouz, A., Sabri, R., \& Hamadouch, N. (2018). Contribution à l'étude de l'hémorragie de la délivrance à la maternité de Centre Hospitalo-Universitaire Ibn Badis. [Contribution to the study of postpartum haemorrhage at the maternity of the Ibn Badis University Hospital Centre]. Master Sciences Biologiques, Université Larbi Ben Mhidi Oum El Bouaghi, République Algerienne Democratique et Populaire. Retrieved September 21, 2020 from http://bib.univ-oeb.dz:8080/jspui/bitstream/123456789/5540/1/M\%c3\%a9moire.pdf

20. Mbeva, J. B. K., Karemere, H., Prudence, M. N., Nyavanda, L., \& Mundama, J. P. (2018). Facteurs explicatifs des décès maternels en milieu hospitalier: une étude au niveau de six zones de santé dans l'Est de la République Démocratique du Congo. [Maternal deaths factors in hospital area: a survey at six health districts in the east of the Republic Democratique of Congo]. International Journal of Innovation and Applied Studies, 23(4), 559-568. Retrieved November 10, 2020 from http://www.ijias.issr-journals.org/abstract.php?article=IJIAS-18$\underline{103-01}$

21. Morau, E., Ducloy, J. C., Le Roux, S., \& Weber, P. (2018). Mortalité maternelle par hémorragie, résultats de l'ENCMM, France 2010-2012. [Maternal deaths due to 
haemorrhage: Results from the French confidential enquiry into maternal deaths, 2010-2012]. Anesthésie \& Réanimation, 4(1), 39-46. https://doi.org/10.1016/j.anrea.2017.11.006.

22. Mukuna, N. B., Okenge, N. L., Sepou, A., \& Modia, O. (2018). Factors Associated with Perinatal Mortality Risk in the Provincial Division of Lomami in the Democratic Republic of Congo. [Facteurs associés au risque de mortalité périnatale dans la Division Provinciale de Lomami en République Démocratique du Congo]. International Journal of Innovation and Applied Studies, 23(4), 434-440. Retrieved November 10, 2020 from http://www.ijias.issrjournals.org/abstract.php?article=IJIAS-18-160-04

23. Nikiema, P. D. (2011). Hémorragies de la période de la délivrance dans le service de gynécologie et d'obstétrique du Centre Hospitalier Universitaire Yalgado Ouedraogo: Aspects épidémio-cliniques et pronostic maternel. À propos de 251 cas. [Postpartum haemorrhage period in the service of gynecology and obstetrics of the University Hospital Center Yalgado Ouedraogo: Epidemiological-clinical aspects and maternal prognosis. About 251 cases]. Doctoral dissertation, Section Médecine Université de Ouagadougou. Retrieved September 22 , 2020

from http://www.beep.ird.fr/collect/uouaga/index/assoc/M12671.dir/M12671.pdf

24. Paillé, P., \& Mucchielli A. (2012). L'analyse qualitative en sciences humaines et sociales. [Qualitative analysis in the humanities and social sciences]. 3e éd. Paris: Armand Colin. Retrieved September 22, 2020 from https://www.cairn.info/l-analyse-qualitative-en-scienceshumaines--9782200249045.htm

25. Randriambelomanana, J. A., Botolahy, Z. A., Rakotoarivony, S. T., Herinirina, S. A. E., Rasataharifetra, H., \& Ratsivalaka, R. (2011). Les hystérectomies obstétricales réalisées au service de Maternité du CHU de Toamasina Madagascar. [The performed obstetrical hysterectomies at the maternity unit of the university hospital of Toamasina Madagascar]. Revue d'Anesthésie-Réanimation et de Médecine d'Urgence, 3(1), 8-11. Retrieved November 10, 2020 from http://rarmu.org/publications/3(1)/full_text/3(1)_8-11.pdf

26. Roman, H., Robillard, P. Y., Verspyck, E., Hulsey, T. C., Sentilhes, L., Marpeau, L., \& Barau, G. (2004). La grande multiparité: excès de risque obstétrical ou neonatal? [The grand multiparity: excess obstetrical or neonatal risk?]. Journal de Gynécologie Obstétrique et Biologie de la Reproduction, 33(4), 347. Retrieved November 10, 2020 from https://www.emconsulte.com/article/115018/la-grande-multiparite-exces-de-risque-obstetrical-

27. Sepou, A., Serdouma, E., Komas, N. P., Gody, C., Abeye, J., Koffi, B., Bangamingo, G., \& Gresenguet, G. (2011). Stratégies de reduction de la mortalité maternelle en République Centrafricaine. Note d'information stratégique. [Strategies to reduce maternal mortality in the Central African Republic. Strategic Information Note]. Retrieved September 22, 2020 from https://www.who.int/evidence/sure/CARPBMM2011.pdf

28. Subtil, D., Sommé, A., Ardiet, E., \& Depret-Mosser, S. (2004). Hémorragies du post-partum: fréquence, conséquences en termes de santé et facteurs de risque avant l'accouchement. [Postpartum haemorrhage: frequency, consequences in terms of health status, and risk factors before delivery]. Journal de Gynécologie Obstétrique et Biologie de la Reproduction, 33(8), 9-16. https://doi.org/10.1016/S0368-2315(04)96644-6.

29. Tessier, V., Leroux, S., \& Guseva-Canu, I. (2017). Mortalité maternelle chez les femmes en situation de précarité. Résultats de l'ENCMM, France 2010-2012. [Maternal deaths related to social vulnerabilities. Results from the French confidential enquiry into maternal deaths, 2010-2012]. Gynécologie Obstétrique Fertilité \& Sénologie, 45(12), S84-S88. https://doi.org/10.1016/j.gofs.2017.10.022. 
30. Thiam, O. (2014). La problématique des parturientes évacuées en zone rurale senegalaise: exemple du centre hospitalier de Ndioum. [The problem of rural evacuated parturients: example of hospital Ndioum (Senegal)]. Revue Africaine et Malgache de Recherche Scientifique/Sciences de la Santé, 1(2), 51-56. Retrieved November 10, 2020 from http://publication.lecames.org/index.php/sante/article/view/97

31. Thorne, S. E. (2008). Interpretive Description. Walnut Creek: Left Cost Press. Retrieved September 22, 2020 from https://www.bookdepository.com/Interpretive-Description-SallyThorne/9781598743302

32. *** Ministère de la santé et de l'hygiène publique (MSHP) [Ministry of Health and Public Hygiene]. (2016). Plan national de développement sanitaire 2016-2020. [National Health Development Plan 2016-2020]. Abidjan, République de Côte d'Ivoire: Draft Consolidé. Retrieved September 21, 2020 from https://www.childrenandaids.org/sites/default/files/201711/pnds_2016-2020.pdf

33. *** Organisation Mondiale de la Santé. [World Health Organization] (2014). Recommandations de l'OMS pour la prévention et le traitement de l'hémorragie du postpartum. [WHO recommendations for prevention and treatment of postpartum haemorrhage]. Genève, Organisation Mondiale de la Santé: Editions de l'Organisation Mondiale de la Santé. $\begin{array}{llll}\text { Retrieved } & \text { September } & 21, & 2020\end{array}$ https://apps.who.int/iris/bitstream/handle/10665/141487/9789242548501_fre.pdf 